\title{
Kajian Peningkatan Keselamatan Pada Simpang Dengan Menerapkan Ruang Henti Khusus Sepeda Motor (Studi Kasus Simpang Empat Bersinyal Srikandi Kabupaten Pasuruan)
}

\section{Safety Improvement Study at the Intersection by Implementing a Special Stop Room for Motorbikes (Case Study of the Srikandi Intersection of the Srikandi Signed Pasuruan Regency)}

\author{
Dwi Muryanto $^{1}$, Yordan Suryoatmojo ${ }^{2}$ \\ ${ }^{1}$ Prodi Teknik Sipil, Fakultas Teknik, Universitas Dr. Soetomo Surabaya, Jl. Semolowaru No. 84, Menur \\ Pumpungan, Kecamatan Sukolilo, Surabaya. Email : dwi.muryanto@unitomo.ac.id \\ ${ }^{2}$ Prodi Teknik Sipil, Fakultas Teknik, Universitas Dr. Soetomo Surabaya, Jl. Semolowaru No. 84, Menur \\ Pumpungan, Kecamatan Sukolilo, Surabaya. Email : yordanpas@gmail.com
}

\begin{abstract}
Abstrak
Pasuruan merupakan salah satu kabupaten di provinsi Jawa Timur yang saat ini mengalami pertumbuhan penduduk dan ekonomi yang cukup tinggi. Dengan adanya pertumbuhan penduduk dan ekonomi yang cukup tinggi tentu akan berpengaruh pada tingkat aktivitas kendaraan bermotor dan arus lalu lintas di ruas jalan terutama pada persimpangan. Dengan meningkatnya aktivitas kendaraan bermotor dan arus lalu lintas akan berpengaruh terhadap kinerja ruas jalan maupun persimpangan. Salah satu simpang yang terpengaruh adalah Simpang Empat Srikandi yang berlokasi di Kecamatan Pandaan. Untuk meningkatkan kinerja pada simpang empat Srikandi perlu dilakukan manajemen lalu lintas. Penelitian ini bertujuan untuk menganalisis kinerja simpang dengan menggunakan perhitungan MKJI 1997 serta menghitung luasan Ruang Henti Khusus (RHK) sepeda motor yang mengacu pada Pedoman Perancangan RHK Sepeda Motor Pada Simpang Bersinyal Di Kawasan Perkotaan. Lengan simpang empat Srikandi yang dikaji adalah Jalan R.A. Kartini dan Jalan A. Yani yang merupakan lengan pendekat terpadat. Metode yang digunakan untuk merencanakan RHK sepeda motor ini menggunakan metode deskriptif kuantitatif dan metode deskriptif kualitatif. Hasil kinerja simpang untuk kondisi eksisting adalah kapasitas pendekat Utara (Jalan Urip Sumoharjo) sebesar 252 smp/jam, panjang antrian $131 \mathrm{~m}$, derajat kejenuhan 0,85. Kapasitas pendekat Timur (Jalan Pahlawan Sunaryo) 265 smp/jam, panjang antrian 146 m, derajat kejenuhan 0,85. Kapasitas pendekat Selatan (Jalan R.A. Kartini) 579 smp/jam, panjang antrian $134 \mathrm{~m}$, derajat kejenuhan 0,85. Kapasitas pendekat Barat (Jalan A. Yani) 730 smp/jam, panjang antrian $104 \mathrm{~m}$, derajat kejenuhan 0,85, sedangkan tundaan rata-rata simpang adalah 59,10 detik/smp. Dari analisis kinerja simpang tersebut, maka diperoleh perhitungan panjang RHK sepeda motor untuk Jalan R.A. Kartini sepanjang 11,5 meter, sedangkan untuk Jalan A. Yani sepanjang 10,3 meter.
\end{abstract}

Kata Kunci: kinerja simpang; simpang empat srikandi; ruang henti khusus

\begin{abstract}
Pasuruan is one of the districts in the province of East Java which is currently experiencing a high population and economic growth. With the high population and economic growth it will certainly affect the level of motorized vehicle activity and the flow of traffic on roads, especially at intersections. With the increase in motor vehicle activity and traffic flow will affect the performance of roads and intersections. One of the affected intersections is the Srikandi Four Intersection which is located in Pandaan District. To improve performance at Srikandi Intersection the traffic management needs to be done. This study aims to analyze the performance of the intersection using the 1997 MKJI calculations and calculate the area of the Special Stop Room (RHK) of a motorcycle that refers to the Guidelines for Designing Motorcycle RHK at Signalized Intersections in Urban Areas. The Srikandi intersection arm that was examined was Jalan R.A. Kartini and Jalan A. Yani which are the densest approach arms. The method used to plan the RHK of this motorcycle uses quantitative descriptive methods and qualitative descriptive methods. The results of the intersection performance for existing conditions
\end{abstract}


are the North approach capacity (Jalan Urip Sumoharjo) of 252 pcu / hour, queue length of $131 \mathrm{~m}$, degree of saturation of 0.85. East approach capacity (Jalan Pahlawan Sunaryo) 265 pcu / hour, queue length $146 \mathrm{~m}$, degree of saturation 0,85. South approach capacity (Jalan R.A. Kartini) 579 pcu / hour, queue length $134 \mathrm{~m}$, degree of saturation of 0.85 . The Western approach capacity (Jalan A. Yani) is $730 \mathrm{pcu} /$ hour, the queue length is $104 \mathrm{~m}$, the degree of saturation is 0.85 , while the average delay is 59.10 seconds / pcu. From the analysis of the performance of the intersection, the length of the RHK motorcycle for the R.A. Kartini is 11.5 meters long, while for Jalan A. Yani it is 10.3 meters long.

Keywords: The performance of the intersection; the intersection of four heroic; special stop space

\section{PENDAHULUAN}

Pasuruan merupakan salah satu kabupaten yang terletak di provinsi Jawa Timur. Letaknya yang strategis yaitu berada pada Jalur Surabaya - Malang serta Surabaya - Bali menyebabkan perkembangan ekonomi di Kabupaten Pasuruan sangat pesat. dalam hal tersebut tentunya akan berdampak terhadap sistem transportasi. Transpotasi merupakan salah satu aspek kehidupan yang mempunyai peranan dalam menunjang bebrbagai kegiatan untuk memenuhi kebutuhan manusia.

Pertumbuhan ekonomi yang pesat ini tentunya berpengaruh pada permasalahan yang semakin kompleks, terutama peningkatan arus lalu lintas pada persimpangan. Kabupaten Pasuruan mempunyai 12 simpang ber-APILL, dan salah satu simpang berAPILL terpadat adalah di Simpang Empat Srikandi yang berlokasi di Kecamatan Pandaan. Simpang Empat Srikandi ini mempunyai arus lalu lintas yang padat karena lokasinya berada di tengah wilayah Perkotaan Pandaan dimana tata guna lahan di sekitarnya adalah daerah pertokoan, pasar, dan pemukiman.

Simpang Empat Srikandi merupakan pertemuan antara ruas Jalan Urip Sumoharjo sebelah utara, ruas Jalan Pahlawan Sunaryo sebelah timur, ruas Jalan R.A. Kartini sebelah selatan, dan ruas Jalan A. Yani sebelah barat. Pengaturan APILL untuk simpang ini adalah dengan 4 fase dalam satu siklus. Selain itu dari ruas jalan R.A. Kartini dan ruas jalan Pahlawan Sunaryo diberlakukan sistem belok kiri langsung (LTOR) yang di tandai dengan rambu-rambu. Dalam pengaturannya, Simpang Empat Srikandi juga dikendalikan dengan sistem ATCS dan pengawasan melalui CCTV.

Untuk mengatasi padatnya kendaraan di Simpang ini serta untuk meningkatkan keselamatan, maka perlu dilakukan manajemen rekayasa lalu lintas yaitu dengan menerapkan Ruang Henti Khusus (RHK) Sepeda Motor.
Tujuan dari penelitian ini adalah untukMenganalisis kinerja lalu lintas eksisting di Simpang 4 Srikandi; meningkatkan keselamatan di Simpang 4 Srikandi Kabupaten Pasuruan dengan menerapkan Ruang Henti Khusus (RHK) sepeda motor; menganalisis dan membandingkan kinerja lalu lintas eksisting dan sesudah diterapannya Ruang Henti Khusus (RHK) sepeda motor.

\section{METODE PENELITIAN}

Pengumpulan data pada kajian dilakukan dengan dua cara yaitu pengumpulan data primer dan sekunder. Metode pengumpulan data sekunder diperoleh dari instansi terkait, berupa peta jaringan jalan, kebijakan pengaturan simpang, angka pertumbuhan kendaraan dan lain-lain.. Pengumpulan data primer yaitu dengan melakukan survai/pengamatan langsung dilapangan untuk mendukung data-data sekunder yang telah diperoleh serta untuk mendapatkan data mengenai geometrik persimpangan dan kondisi lalu lintas eksisting. Data yang telah diperoleh selanjutnya diolah dengan menggunakan analisa sebagai berikut :

\section{Metode Deskriptif Kuantitatif}

Metotde Deskriptif Kuantitatif menjelaskan isi dari penelitian ini yang terdiri dari rumusan masalah, landasan teori, pegumpulan data, analisis data, dan kesimpulan serta saran.

\section{Metode Deskriptif Kualitatif}

Metode Deskriptif Kualitatif bertujuan untuk menjawab rumusan masalah dari penelitian ini yang meliputi : kinerja lalu lintas eksisting di Simpang 4 Srikandi, bagaimana cara meningkatkan keselamatan di Simpang 4 Srikandi, serta perbandingan kinerja lalu lintas eksisting dan sesudah diterapkannya Ruang Henti Khusus (RHK) sepeda motor.

Dalam melakukan pengelolaan data pada penelitian ini dilakukan analisis kinerja simpang kondisi eksisting dan analisis penghitungan dimensi RHK. 


\section{Analisis Kinerja Simpang Kondisi Eksisting}

Analisis kinerja simpang meliputi : Kapasitas, Arus Jenuh, Derajat Kejenuhan, Jumlah Antrian, Panjang Antrian, Kendaraan terhenti, Tundaan, dan Tingkat Pelayanan / Level Of Service (LOS).

\section{Analisis Penghitungan Dimensi RHK}

Analisis Penghitungan Dimensi RHK meliputi : Desain Ruang Henti Khusus (RHK) Sepeda Motor, Usulan Kondisi Alternatif Setelah Penerapan RHK, serta Perbandingan Kondisi Eksisting Dengan Setelah Diterapkannya Ruang Henti Khusus Pada Simpang Empat Srikandi.

\section{HASIL PENELITIAN DAN PEMBAHASAN Data Geometrik Simpang}

Tabel 1. Geometrik Simpang Empat Srikandi Kondisi Eksisrting Tahun 2019

\begin{tabular}{|l|c|c|c|c|}
\hline \multicolumn{1}{|c|}{ PENDEKAT } & UTARA & TIMUR & SELATAN & BARAT \\
\hline Tipe Lingkungan Jalan & COM & COM & COM & COM \\
\hline Hambatan Samping & Sedang & Tinggi & Sedang & Sedang \\
\hline Median & Tidak Ada & Ada & Tidak Ada & Ada \\
\hline $\begin{array}{l}\text { Belok Kiri Jalan Terus } \\
\text { (LTOR) }\end{array}$ & Tidak & Ya & Ya & Tidak \\
\hline Lebar Pendekat (m) & 2,50 & 7,00 & 2,50 & 7,00 \\
\hline Lebar Pendekat Masuk (m) & 2,50 & 4,00 & 2,50 & 7,00 \\
\hline Lebar Pendekat LTOR (m) & 0,00 & 2,40 & 0,00 & 0,00 \\
\hline Lebar Pendekat Keluar (m) & 7,00 & 2,50 & 7,00 & 2,50 \\
\hline
\end{tabular}

Sumber : Survei Data Primer, 2019

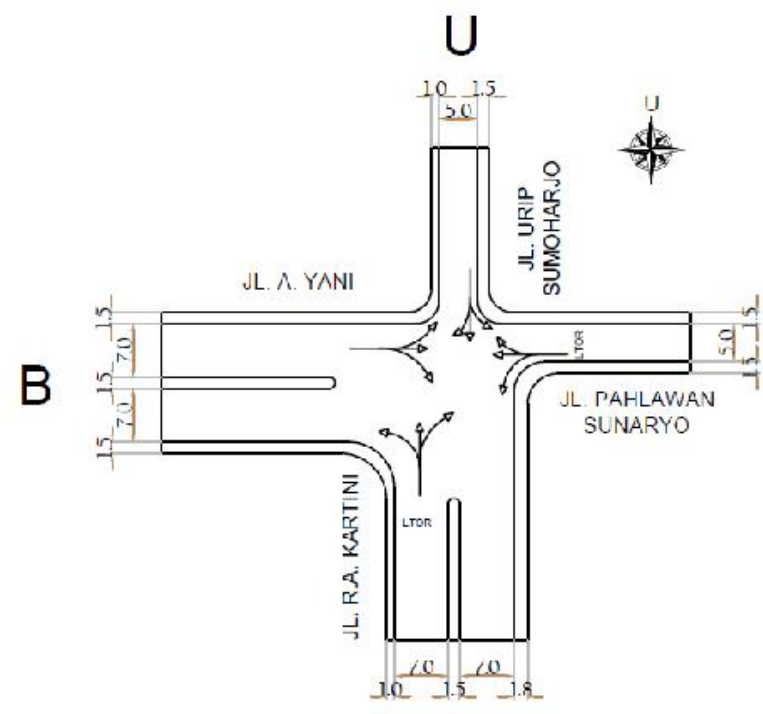

$S$

Gambar 1. Kondisi Geometrik Simpang Empat Srikandi

Sumber : Survei Data Primer, 2019

\section{Data Volume Lalu Lintas}

Survai gerakan membelok terklasifikasi dilakukan pada hari kerja (Selasa) dan hari libur (Minggu) yang dilakukan pada jam puncak pagi pukul 06.00 $08.00 \mathrm{WIB}$, puncak siang pukul $12.00-14.00 \mathrm{WIB}$, puncak sore pukul 16.00 - 18.00 WIB. Sedangkan untuk kendaraan yang disurvei dibagi menjadi empat jenis yaitu : Kendaraan ringan (mobil pribadi, pick up, MPU), Kendaraan berat (truk dan bus), Sepeda motor, dan Kendaraan tidak bermotor. Adapun hasil rekapitulasi Penghitungan volume lalu lintas gerakan membelok sebagai berikut :

Tabel 2. Volume Kendaraan Tertinggi Jam Puncak Kondisi Eksisting Tahun 2019 (kend/jam)

\begin{tabular}{|c|l|c|c|c|c|c|}
\hline No & Nama Jalan & $\begin{array}{c}\text { Kendaraa } \\
\text { n Ringan }\end{array}$ & $\begin{array}{c}\text { Kendaraa } \\
\text { Berat }\end{array}$ & $\begin{array}{c}\text { Sepeda } \\
\text { Motor }\end{array}$ & $\begin{array}{c}\text { Kend. } \\
\text { Tidak } \\
\text { Bermot } \\
\text { or }\end{array}$ & $\begin{array}{c}\text { Juml } \\
\text { ah }\end{array}$ \\
\hline 1 & $\begin{array}{l}\text { JL. URIP } \\
\text { SUMOHARJO }\end{array}$ & 109 & 14 & 452 & 41 & 616 \\
\hline 2 & $\begin{array}{l}\text { JL. PAHLAWAN } \\
\text { SUNARYO }\end{array}$ & 105 & 4 & 572 & 16 & 697 \\
\hline 3 & JL. R.A. KARTINI & 285 & 26 & 860 & 43 & 1.214 \\
\hline 4 & JL. A. YANI & 317 & 58 & 1131 & 62 & 1.568 \\
\hline & \multicolumn{1}{|c|}{ Total } & 816 & 102 & 3.01 & 162 & 4.095 \\
\hline
\end{tabular}

Sumber : Hasil Analisis, 2019

Tabel 3. Volume Kendaraan Tertinggi Pada Hari Libur Pada Saat Jam Puncak Kondisi Eksisting Tahun 2019 (kend/jam)

\begin{tabular}{|c|l|c|c|c|c|c|}
\hline No & Nama Jalan & $\begin{array}{c}\text { Kendaraa } \\
\text { n Ringan }\end{array}$ & $\begin{array}{c}\text { Kendaraa } \\
\text { Berat }\end{array}$ & $\begin{array}{c}\text { Sepeda } \\
\text { Motor }\end{array}$ & $\begin{array}{c}\text { Kend. } \\
\text { Tidak } \\
\text { Bermot } \\
\text { or }\end{array}$ & $\begin{array}{c}\text { Juml } \\
\text { ah }\end{array}$ \\
\hline 1 & $\begin{array}{l}\text { JL. URIP } \\
\text { SUMOHARJO }\end{array}$ & 126 & 8 & 553 & 23 & 710 \\
\hline 2 & $\begin{array}{l}\text { JL. PAHLAWAN } \\
\text { SUNARYO }\end{array}$ & 99 & 3 & 591 & 32 & 725 \\
\hline 3 & JL. R.A. KARTINI & 193 & 30 & 608 & 56 & 887 \\
\hline 4 & JL. A. YANI & 153 & 32 & 653 & 37 & 875 \\
\hline & Total & 571 & 73 & 2.405 & 148 & 3.197 \\
\hline
\end{tabular}

Sumber : Hasil Analisis, 2019

Berdasarkan tabel 2 dan tabel 3, diketahui volume lalu lintas tertinggi adalah pada hari efektif T (hari kerja), maka akan dijadikan dasar Penghitungan pada analisa selanjutnya.

Jalan Urip Sumoharjo (lengan Utara)

Tabel 4. Proporsi Arah Pergerakan Kendaraan Dari Jalan Urip Sumoharjo Pada Jam Tersibuk Kondisi Eksisting Tahun 2019 (kend/jam)

\begin{tabular}{|l|c|c|c|c|c|}
\hline \multirow{2}{*}{ Jenis Kendaraan } & \multicolumn{2}{|c|}{ Arah Gerak Kendaraan } & \multirow{2}{*}{ Jumlah } & Prosentase \\
\cline { 2 - 5 } & Kiri & Lurus & Kanan & & \\
\hline Kendaraan Ringan & 7 & 62 & 40 & 109 & $18 \%$ \\
\hline Kendaraan Berat & 3 & 6 & 5 & 14 & $2 \%$ \\
\hline Sepeda Motor & 79 & 207 & 166 & 452 & $73 \%$ \\
\hline $\begin{array}{l}\text { Kendaraan Tidak } \\
\text { Bermotor }\end{array}$ & 10 & 18 & 13 & 41 & $7 \%$ \\
\hline Jumlah & 99 & 293 & 224 & 616 & $100 \%$ \\
\hline
\end{tabular}




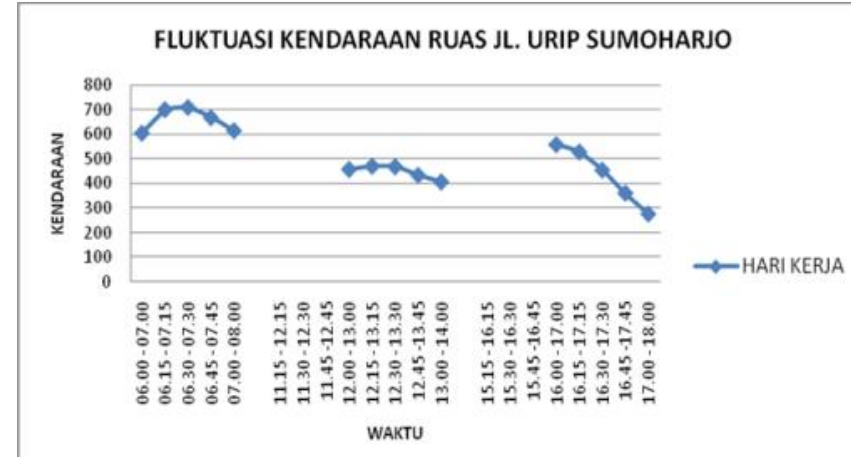

Gambar 2. Fluktuasi Volume Kendaraan Di Jalan Urip Sumoharjo

Sumber : Hasil Analisis, 2019

\section{Jalan Pahlawan Sunaryo (lengan Timur)}

Tabel 5. Proporsi Arah Pergerakan Kendaraan Dari Jalan Pahlawan Sunaryo Pada Jam Tersibuk Kondisi Eksisting Tahun 2019 (kend/jam)

\begin{tabular}{|c|c|c|c|c|c|}
\hline \multirow{2}{*}{ Jenis Kendaraan } & \multicolumn{3}{|c|}{$\begin{array}{c}\text { Arah Gerak } \\
\text { Kendaraan }\end{array}$} & \multirow{2}{*}{ Jumlah } & \multirow{2}{*}{$\begin{array}{c}\text { Prosentas } \\
\mathrm{e}\end{array}$} \\
\hline & Kiri & Lurus & Kanan & & \\
\hline Kendaraan Ringan & 44 & 55 & 6 & 105 & $15 \%$ \\
\hline Kendaraan Berat & 2 & 2 & 0 & 4 & $1 \%$ \\
\hline Sepeda Motor & 293 & 239 & 40 & 572 & $82 \%$ \\
\hline $\begin{array}{l}\text { Kendaraan Tidak } \\
\text { Bermotor }\end{array}$ & 8 & 4 & 4 & 16 & $2 \%$ \\
\hline Jumlah & 347 & 300 & 50 & 697 & $100 \%$ \\
\hline
\end{tabular}

Sumber : Hasil Analisis, 2019

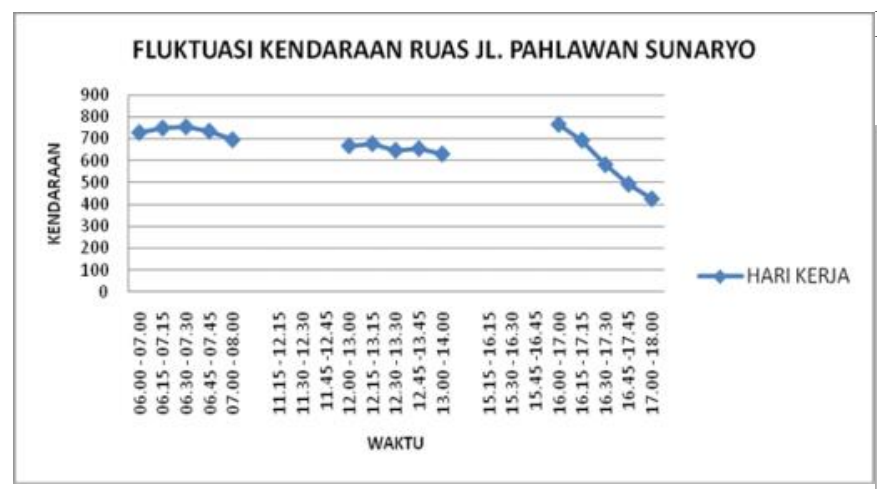

Gambar 3. Fluktuasi Volume Kendaraan Di Jalan Pahlawan Sunaryo

Jalan A. Yani (lengan Barat)

Tabel 6. Proporsi Arah Pergerakan Kendaraan Dari Jalan A. Yani Pada Jam Tersibuk Kondisi Eksisting tahun 2019 (kend/jam)

\begin{tabular}{|l|c|c|c|c|c|}
\hline \multirow{2}{*}{ Jenis Kendaraan } & \multicolumn{3}{|c|}{ Arah Gerak Kendaraan } & \multirow{2}{*}{ Jumlah } & \multirow{2}{*}{ Prosentase } \\
\cline { 2 - 6 } & Kiri & Lurus & Kanan & & \\
\hline Kendaraan Ringan & 14 & 147 & 156 & 317 & $20 \%$ \\
\hline Kendaraan Berat & 0 & 8 & 50 & 58 & $4 \%$ \\
\hline Sepeda Motor & 214 & 411 & 506 & 1131 & $72 \%$ \\
\hline
\end{tabular}

\section{Jalan R.A. Kartini (lengan Selatan)}

Tabel 7. Proporsi Arah Pergerakan Kendaraan Dari Jalan R.A. Kartini Pada Jam Tersibuk Kondisi Eksisting Tahun 2019 (kend/jam)

\begin{tabular}{|c|c|c|c|c|c|}
\hline \multirow{2}{*}{ Jenis Kendaraan } & \multicolumn{3}{|c|}{$\begin{array}{c}\text { Arah Gerak } \\
\text { Kendaraan }\end{array}$} & \multirow[t]{2}{*}{ Jumlah } & \multirow{2}{*}{$\begin{array}{c}\text { Prosentas } \\
\mathrm{e}\end{array}$} \\
\hline & Kiri & Lurus & Kanan & & \\
\hline Kendaraan Ringan & 103 & 88 & 94 & 285 & $23 \%$ \\
\hline Kendaraan Berat & 22 & 1 & 3 & 26 & $2 \%$ \\
\hline Sepeda Motor & 379 & 203 & 278 & 860 & $71 \%$ \\
\hline $\begin{array}{l}\text { Kendaraan Tidak } \\
\text { Bermotor }\end{array}$ & 20 & 11 & 12 & 43 & $4 \%$ \\
\hline Jumlah & 524 & 303 & 387 & 1214 & $100 \%$ \\
\hline
\end{tabular}

Sumber : Hasil Analisis, 2019

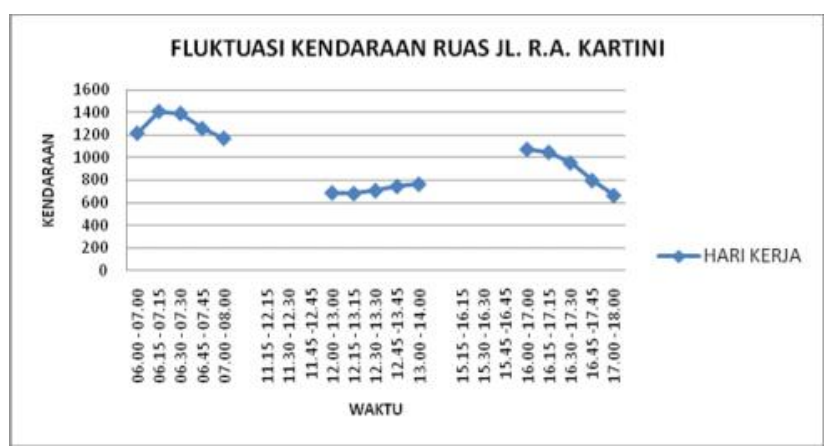

Gambar 4. Fluktuasi Volume Kendaraan Di Jalan R.A. Kartini

Sumber : Hasil Analisis, 2019

\section{Data Pengaturan Traffic Light (APILL)}

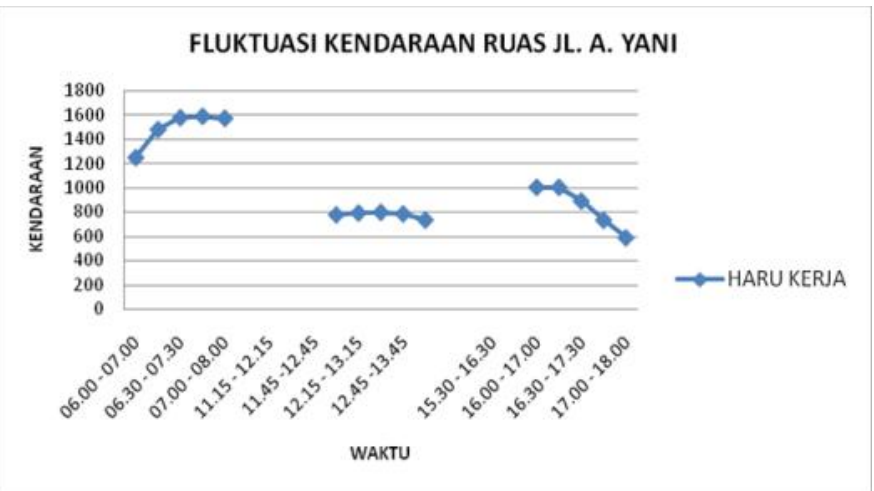

Gambar 5. Fluktuasi Volume Kendaraan Di Jalan A. Yani 


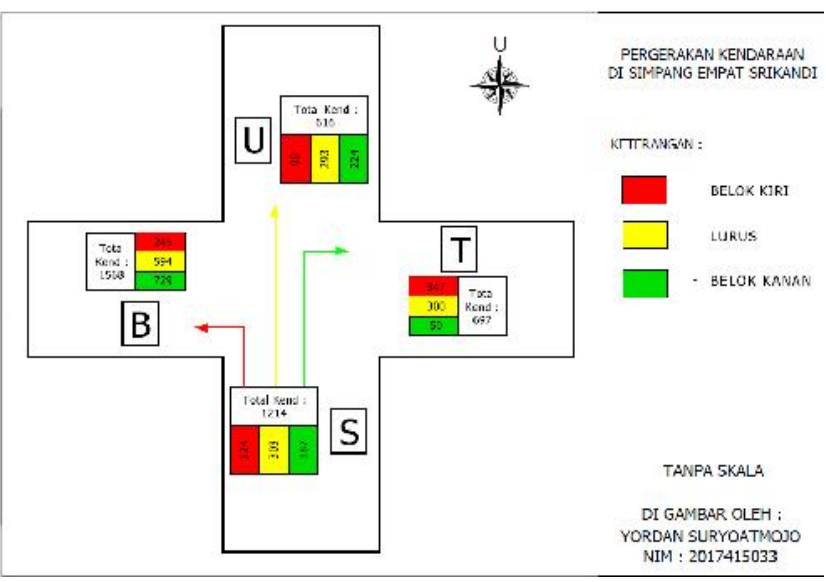

Gambar 6. Pergerakan Kendaraan Di Simpang Empat Srikandi pada jam tersibuk tahun 2019

Sumber : Hasil Analisis, 2019

Dari gambar 6. dapat diketahui Volume lalu lintas di Simpang Empat Srikandi. Pergerakan kendaraan tertinggi adalah pada pendekat Barat (ruas Jalan A.Yani) dengan total pergerakan sebesar 1.568 kendaraan.

Tabel 8. Hasil Analisis Kinerja Simpang 4 Bersinyal Eksisiting Tahun 2019

\begin{tabular}{|l|c|c|c|c|}
\hline \multicolumn{1}{|c|}{ URAIAN } & U & T & S & B \\
\hline Waktu Hijau (dt) & 22 & 31 & 37 & 22 \\
\hline Waktu Siklus (dt) & \multicolumn{5}{|c|}{136} \\
\hline Kapasitas C (smp/jam) & 252 & 578 & 265 & 736 \\
\hline Derajat Kejenuhan DS & 0,85 & 0,85 & 0,85 & 0,85 \\
\hline Panjang antrian (m) & 131 & 146 & 134 & 104 \\
\hline Rata - rata Tundaan (detik/smp) & \multicolumn{5}{|c|}{59,10} \\
\hline Level Of Service (LOS) & \multicolumn{5}{|c|}{ E } \\
\hline
\end{tabular}

Sumber : Hasil Analisis, 2019

Desain Ruang Henti Khusus (RHK) Sepeda Motor

Penerapan Ruang Henti Khusus (RHK) Sepeda Motor adalah pada ruas Jalan R.A. Kartini dan ruas Jalan A. Yani.

\section{Jalan R.A Kartini (lengan Pendekat Selatan)}

Tabel 9. Penghitungan Dimensi RHK Jalan R.A. Kartini

\begin{tabular}{|l|l|c|c|}
\hline \multicolumn{1}{|c|}{ Uraian } & \multicolumn{1}{|c|}{ Satuan } & Ukuran & Pembulatan \\
\hline Lebar pendekat & meter & 4,00 & \\
\hline $\begin{array}{l}\text { Arus sepeda motor per jam } \\
\text { sibuk }\end{array}$ & $\begin{array}{l}\text { Q (seped } \\
\text { motor) }\end{array}$ & 860 & \\
\hline waktu siklus & detik & 136 & \\
\hline $\begin{array}{l}\text { jumlah fase hijau per jam } \\
\text { sibuk }\end{array}$ & $\mathrm{n}(\mathrm{g})$ & 26,44 & \\
\hline $\begin{array}{l}\text { jumlah sepeda motor per } \\
\text { siklus }\end{array}$ & $\begin{array}{l}\text { n (sepeda } \\
\text { motor) }\end{array}$ & 32,53 & 33 \\
\hline
\end{tabular}

\begin{tabular}{|l|l|c|c|}
$\begin{array}{l}\text { panjang ruang statis sepeda } \\
\text { motor }\end{array}$ & meter & 2 & \\
\hline $\begin{array}{l}\text { lebar ruang statis sepeda } \\
\text { motor }\end{array}$ & meter & 0,75 & \\
\hline $\begin{array}{l}\text { jumlah SPM per lebar } \\
\text { pendekat }\end{array}$ & $\begin{array}{l}\text { C (sepeda } \\
\text { motor) }\end{array}$ & 5,33 & 6 \\
\hline panjang RHK & meter & 11 & 11,5 \\
\hline
\end{tabular}

Sumber : Hasil Analisis, 2019

Tabel 10. Dimensi RHK dan Perubahan Jarak Garis Henti Ke Titik Konflik

\begin{tabular}{|l|c|c|}
\hline \multicolumn{1}{|c|}{ Uraian } & Satuan & Ukuran \\
\hline lebar zebra cross & meter & 2,5 \\
\hline jarak stop line dengan zebra cross & meter & 0,3 \\
\hline lebar stop line RHK & meter & 0,3 \\
\hline panjang RHK & meter & 11,5 \\
\hline $\begin{array}{l}\text { lebar stopline kendaraan selain sepeda } \\
\text { motor }\end{array}$ & meter & 0,3 \\
\hline panjang lajur khusus sepeda motor & meter & \\
\hline lebar lajur khusus sepeda motor & meter & 1.8 \\
\hline LEV eksisting & meter & 35,47 \\
\hline LAV eksisting & meter & 30,32 \\
\hline $\begin{array}{l}\text { LEV bagi LV dan HV setelah adanya } \\
\text { RHK }\end{array}$ & meter & 47,57 \\
\hline $\begin{array}{l}\text { LAV bagi LV dan HV setelah adanya } \\
\text { RHK }\end{array}$ & meter & 41,20 \\
\hline
\end{tabular}

Sumber : Hasil Analisis, 2019

Dari hasil penghitungan dimensi RHK pada Jl. R.A. Kartini di dapat untuk panjang RHK yang akan di terapkan adalah 11 meter. Untuk mempermudah manuver sepeda motor memasuki RHK ketika sudah ada kendaraan roda empat di belakang RHK maka ditambahkan 0,5 meter lagi sebagai antisipasi apabila kendaraan roda empat tiba lebih dulu dan RHK sudah hampir penuh dengan sepeda motor. Sehingga panjang RHK untuk pendekat Selatan adalah sebesar 11,5 meter. Desain gambar RHK untuk Jl. R.A. Kartini adalah sebagai berikut :

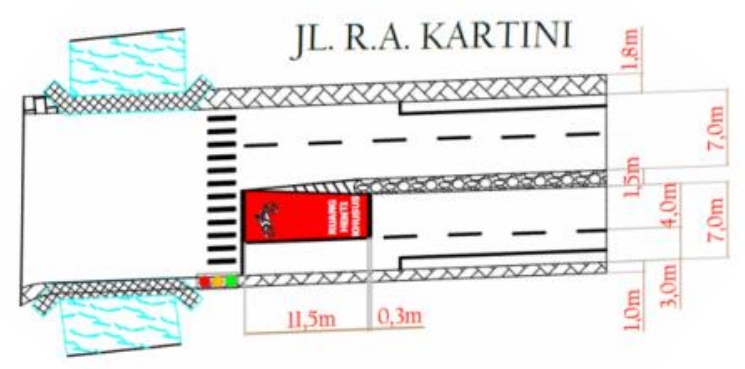

Gambar 7. Dimensi desain RHK jalan RA. Kartini Sumber : Hasil Analisis, 2019 
Jalan A. Yani ( lengan Pendekat Barat)

Tabel 11. Penghitungan Dimensi RHK Jalan A. Yani

\begin{tabular}{|l|l|c|c|}
\hline \multicolumn{1}{|c|}{ Uraian } & \multicolumn{1}{c|}{ Satuan } & Ukuran & Pembulatan \\
\hline Lebar pendekat & meter & 7,00 & \\
\hline Arus sepeda motor per jam sibuk & Q (sepeda motor) & 1162 & \\
\hline waktu siklus & detik & 136 & \\
\hline jumlah fase hijau per jam sibuk & $\mathrm{n}(\mathrm{g})$ & 26,44 & \\
\hline jumlah sepeda motor per siklus & $\mathrm{n}$ (sepeda motor) & 43,95 & 44 \\
\hline $\begin{array}{l}\text { panjang ruang statis sepeda } \\
\text { motor }\end{array}$ & meter & 2 & \\
\hline lebar ruang statis sepeda motor & meter & 0,75 & \\
\hline jumlah SPM per lebar pendekat & C (sepeda motor) & 9,33 & 9 \\
\hline panjang RHK & meter & 9,8 & 10,3 \\
\hline
\end{tabular}

Sumber : Hasil Analisis, 2019

Tabel 12. Dimensi RHK dan Perubahan Jarak Garis Henti Ke Titik Konflik

\begin{tabular}{|l|c|c|}
\hline \multicolumn{1}{|c|}{ Uraian } & Satuan & Ukuran \\
\hline lebar zebra cross & meter & 2,5 \\
\hline jarak stop line dengan zebra cross & meter & 0,3 \\
\hline lebar stop line RHK & meter & 0,3 \\
\hline panjang RHK & meter & 10,28 \\
\hline $\begin{array}{l}\text { lebar stopline kendaraan selain sepeda } \\
\text { motor }\end{array}$ & meter & 0,3 \\
\hline panjang lajur khusus sepeda motor & meter & \\
\hline lebar lajur khusus sepeda motor & meter & 1.8 \\
\hline LEV eksisting & meter & 38,45 \\
\hline LAV eksisting & meter & 37,89 \\
\hline EV bagi LV dan HV setelah adanya RHK & meter & 49,33 \\
\hline $\begin{array}{l}\text { LAV bagi LV dan HV setelah adanya } \\
\text { RHK }\end{array}$ & meter & 37,89 \\
\hline
\end{tabular}

Sumber : Hasil Analisis, 2019

Dari hasil penghitungan dimensi RHK pada Jl. A. Yani di dapat untuk panjang RHK yang akan di terapkan adalah 9,8 meter dan ditambahkan 0,5 meter menjadi 10,3 meter.

Untuk mempermudah manuver sepeda motor memasuki RHK ketika sudah ada kendaraan roda empat di belakang RHK maka ditambahkan 0,5 meter lagi sebagai antisipasi apabila kendaraan roda empat tiba lebih dulu dan RHK sudah hampir penuh dengan sepeda motor.

RHK pada Jl. A. Yani di dapat untuk panjang RHK yang akan di terapkan adalah 9,8 meter dan ditambahkan 0,5 meter menjadi 10,3 meter. Desain gambar RHK untuk Jl. A. Yani adalah sebagai berikut :

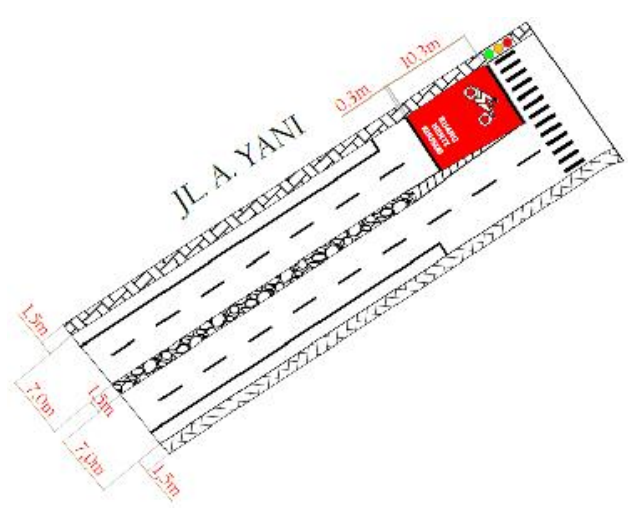

Gambar 8. Dimensi desain RHK Jalan A. Yani Sumber : Hasil Analisis (2019)

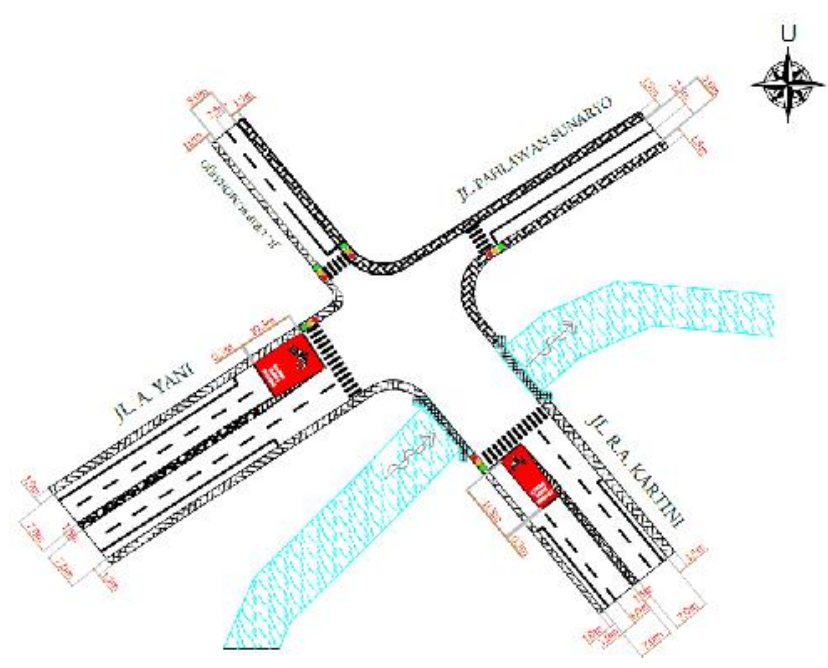

Gambar 9. Desain RHK Simpang Empat Srikandi Sumber : Hasil Analisis, 2019

\section{Usulan Kondisi Alternatif Setelah Penerapan RHK}

Berdasarkan hasil analisa desain RHK maka perlu dipertimbangkan juga pengaturan lain yang diperlukan agar lebih tercipta ketertiban berlalu lintas dan peningkatan kinerja simpang tersebut.

Alternatif pertama, yaitu tidak merubah fase yang sudah ada yaitu tetap 4 fase 
Tabel 13.Hasil Evaluasi Kinerja Simpang 4 Bersinyal Alternatif 1

\begin{tabular}{|l|c|c|c|c|}
\hline \multicolumn{1}{|c|}{ URAIAN } & U & T & S & B \\
\hline Waktu Hijau (dt) & 15 & 20 & 25 & 25 \\
\hline Waktu Siklus (dt) & \multicolumn{4}{c|}{109} \\
\hline Kapasitas C (smp/jam) & 311 & 830 & 332 & 1056 \\
\hline Derajat Kejenuhan DS & 0,69 & 0,68 & 0,59 & 0,59 \\
\hline Panjang antrian (m) & 91 & 94 & 87 & 65 \\
\hline Rata - rata Tundaan (detik/smp) & \multicolumn{5}{|c|}{23,77} \\
\hline Level Of Service (LOS) & \multicolumn{5}{|c|}{} \\
\hline Sumber : Hasil Analisis, 2019 & \multicolumn{5}{|c|}{} \\
\hline
\end{tabular}

Dari hasil evaluasi alternatif 1 dengan tidak merubah fase dan melakukan evaluasi waktu siklus dari 136 detik menjadi 109 detik, maka didapat hasil kinerja simpang bersinyal yang lebih baik, dengan penurunan rata rata tundaan simpang yang semula $59,10 \mathrm{detik} / \mathrm{smp}$ menjadi 23,77 detik/smp dan peningkatan dari level of service $\mathrm{E}$ menjadi level of service $\mathrm{C}$.

Alternatif kedua, yaitu mengubah kondisi existing yang semula 4 fase menjadi 3 fase

Tabel 14.Hasil Evaluasi Kinerja Simpang 4 Bersinyal Alternatif 2

\begin{tabular}{|l|c|c|c|c|}
\hline \multicolumn{1}{|c|}{ URAIAN } & U & S & T & B \\
\hline Waktu Hijau (dt) & \multicolumn{2}{|c|}{24} & 17 & 20 \\
\hline Waktu Siklus (dt) & \multicolumn{5}{|c|}{82} \\
\hline Kapasitas C (smp/jam) & 448 & 392 & 928 & 1123 \\
\hline Derajat Kejenuhan DS & 0,48 & 0,53 & 0,57 & 0,56 \\
\hline Panjang antrian (m) & 71 & 51 & 84 & 36 \\
\hline Rata - rata Tundaan (detik/smp) & \multicolumn{5}{|c|}{14,46} \\
\hline Level Of Service (LOS) & \multicolumn{5}{|c|}{ B } \\
\hline
\end{tabular}

Sumber : Hasil Analisis, 2019

Dari hasil evaluasi alternatif 2 dengan merubah fase dari 4 fase menjadi 3 fase dan melakukan evaluasi waktu siklus dari 136 detik menjadi 82 detik, maka didapat hasil kinerja simpang bersinyal yang lebih baik, dengan penurunan rata rata tundaan simpang yang semula $59,10 \mathrm{detik} / \mathrm{smp}$ menjadi 14,46 detik/smp dan peningkatan dari level of service $\mathrm{E}$ menjadi level of service $\mathrm{B}$.

\section{Perbandingan Kondisi Eksisting Dengan Setelah Diterapkannya RHK Sepeda Motor}

Alternatif 1 dan 2 dapat meningkatkan kinerja simpang bila dilihat dari indikator panjang antrian, derajat kejenuhan dan tundaan rata-rata simpang. Dengan pengaturan waktu siklus dan fase APILL,selengkapnya dapat dilihat pada tabel 15.
Tabel 15. Perbandingan Hasil Penghitungan Kondisi

\begin{tabular}{|c|c|c|c|c|c|c|c|c|c|c|}
\hline & \multicolumn{10}{|c|}{ xisting dan Alternatif } \\
\hline & \multirow{4}{*}{$\begin{array}{c}\text { KAKI } \\
\text { SIMPANG }\end{array}$} & \multicolumn{3}{|c|}{$\begin{array}{l}\text { PANJANG } \\
\text { ANTRIAN } \\
\text { QL (meter) }\end{array}$} & \multicolumn{3}{|c|}{$\begin{array}{l}\text { DERAJAT } \\
\text { KEJENUHAN }\end{array}$} & \multicolumn{3}{|c|}{$\begin{array}{l}\text { TUNDAAN } \\
\text { RATA-RATA } \\
\text { SIMPANG } \\
\text { (DETIK/SMP) }\end{array}$} \\
\hline & & \multicolumn{3}{|c|}{ KONDISI } & \multicolumn{3}{|c|}{ KONDISI } & \multicolumn{3}{|c|}{ KONDISI } \\
\hline & & \multicolumn{3}{|c|}{\begin{tabular}{|l|l|} 
& ALTE \\
EXIS RNAT & RNAT \\
TING & F
\end{tabular}} & \multirow[t]{2}{*}{\begin{tabular}{|l} 
EXIS \\
TING
\end{tabular}} & \multicolumn{2}{|c|}{$\begin{array}{l}\text { ALTERNA } \\
\text { TIF }\end{array}$} & \multirow{2}{*}{$\begin{array}{l}\text { EXIS } \\
\text { TING }\end{array}$} & \multicolumn{2}{|c|}{$\begin{array}{l}\text { ALTERNA } \\
\text { TIF }\end{array}$} \\
\hline & & & & 2 & & 1 & 2 & & 1 & 2 \\
\hline 1 & $\begin{array}{c}\text { JL. URIP } \\
\text { SUMOHARJ } \\
\text { O }\end{array}$ & 131 & 91 & 71 & 0,85 & 0,69 & 0,48 & & & \\
\hline 2 & \begin{tabular}{|c|} 
JL. \\
PAHLAWA \\
N \\
SUNARYO \\
\end{tabular} & 146 & 94 & 84 & 0,85 & 0,68 & 0,57 & & & \\
\hline 3 & $\begin{array}{l}\text { JL. R.A. } \\
\text { KARTINI }\end{array}$ & 134 & 87 & 51 & 0,85 & 0,59 & 0,53 & & & \\
\hline 4 & JL. A. YANI & 104 & 65 & 36 & 85 & 0,59 & 0,56 & & & \\
\hline & ATA-RATA & 129 & 84 & 61 & 0,85 & 0,64 & 0,53 & & & \\
\hline
\end{tabular}

Sumber : Hasil Analisis, 2019

Dari tabel 15 dapat dilihat bahwa alternatif 1 dan 2 dapat meningkatkan kinerja simpang bila dilihat dari indikator panjang antrian, derajat kejenuhan dan tundaan rata-rata simpang. Dengan pengaturan waktu siklus dan fase APILL, seluruh alternatif diatas bisa diterapkan untuk RHK yang telah didesain untuk Simpang Empat Srikandi.

\section{KESIMPULAN DAN SARAN}

\section{Kesimpulan}

Dari analisis yang telah dilakukan, diperoleh hasil sebagai berikut, kondisi existing Simpang Empat Srikandi. Pendekat Utara (Jalan Urip Sumoharjo) kapasitas $=252 \mathrm{smp} / \mathrm{jam}$; panjang antrian $131 \mathrm{~m}$; derajat kejenuhan 0,85 . Pendekat Timur (Jalan Pahlawan Sunaryo) kapasitas $=265 \mathrm{smp} / \mathrm{jam}$; panjang antrian $146 \mathrm{~m}$; derajat kejenuhan 0,85 . Pendekat Selatan (Jalan R.A. Kartini) kapasitas = 579 smp/jam; panjang antrian $134 \mathrm{~m}$; derajat kejenuhan 0,85. Pendekat Barat (Jalan A. Yani) kapasitas $=730 \mathrm{smp} / \mathrm{jam}$; panjang antrian $104 \mathrm{~m}$; derajat kejenuhan 0,85 .

Sedangkan tundaan rata-rata simpang adalah 59,10 detik/smp. Dari hasil analisis tundaan rata-rata tersebut maka simpang Empat Srikandi masuk dalam tingkat pelayanan (level of service) E yaitu antara nilai 40,1 - 60 detik/smp dengan kategori buruk.

Perencanaan penerapan Ruang Henti Khusus sepeda motor di Simpang Empat Srikandi adalah pada ruas Jalan R.A. Kartini dan ruas Jalan A. Yani. Dengan panjang Ruang Henti Khusus sepeda motor untuk ruas Jalan R.A. Kartini sepanjang 11,5 meter, Proteksi/Juni 2020 Volume 2 No. 1 
sedangkan untuk ruas Jalan A. Yani sepanjang 10,3 meter.

Penerapan Ruang Henti Khusus sepeda motor pada Simpang Empat Srikandi serta pengaturan siklus APILL alternatif 1, maka dapat menurunkan panjang antrian rata-rata menjadi 84 meter, derajat kejenuhan 0,64 , tundaan rata-rata simpang menjadi 23,77 detik/smp.

\section{Saran}

Untuk tercapainya penerapan Ruang Henti Khusus (RHK) sepeda motor secara maksimal, berikut beberapa saran dari studi ini antara lain :

Penerapan Ruang Henti Khusus sepeda motor lebih baik menggunakan alternatif 1 dengan menerapkan 4 fase dalam 1 siklus karena dapat meningkatkan keselamatan dengan menurunkan konflik dalam persimpangan.

Untuk memperoleh hasil yang maksimal perlu dilakukan koordinasi antar instansi dalam melakukan perencanaan penerapan Ruang Henti Khusus.

Perlunya dilakukan sosialisasi kepada masyarakat, terutama pada pengguna kendaraan bermotor. Sosialisasi dapat dilakukan dengan memasang spanduk, sticker, serta sosialisasi kepada pelajar dan mahasiswa dengan harapan masyarakat tidak hanya mengerti fungsi RHK namun juga memahami perihal keselamatan dalam berlalu lintas.

Apabila Ruang Henti Khusus (RHK) sepeda motor sudah di terapkan dan di sosialisasikan, maka harus ada pengawasan dari pihak yang berwenang agar tercipta lalu lintas yang tertib dan lancar.

\section{DAFTAR PUSTAKA}

Amelia, Sri. 2016. "Kebijakan Penerapan Ruang Henti Khusus Sepeda Motor", Simposium Nasional Teknologi Terapan (SNTT), Pusat Penelitian dan Pengembangan Jalan dan Jembatan, April, Bandung.

Astuti, Naomi, Purba dan Jeluddin Daud. 2013. "Perencanaan Ruang Henti Khusus (RHK) Sepeda Motor Pada Persimpangan Bersinyal Di Medan (Studi Kasus : Persimpangan J1. Ir. H. Juanda - J1. Brigjend Katamso)", Jurnal Purba, Vol.3, No.1, 2014, Jurusan Teknik Sipil USU, Medan.

Ayu, Reska, Yuniar, dkk. 2016. "Analisis Efektivitas Ruang Henti Khusus Sepeda Motor Pada Simpang Bersinyal Di Kota Semarang", Jurnal Karya Teknik Sipil, Vol.5, No.2, 2016, Hal
128-137, Jurusan Teknik Sipil UNDIP, Semarang.

Balai Teknik Lalu Lintas dan Lingkungan Jalan. 2012. "Modul Pelatihan Perancangan RHK". Pusat Penelitian dan Pengembangan Jalan dan Jembatan. Bandung.

Departemen Perhubungan. 2004. "Undang-Undang Nomor 38 Tahun 2004 tentang Jalan”. Jakarta.

Departemen Perhubungan. 2009. "Undang-Undang Nomor 22 Tahun 2009 tentang Lalu Lintas dan Angkutan Jalan". Jakarta.

Direktorat Jendral Bina Marga. 1997. "Manual Kapasitas Jalan Indonesia”. Jakarta.

Idris, M. 2007. "Pengaruh Ruang Henti Khusus Sepeda Motor Terhadap Konflik Lalu Lintas Pada Satu Persimpangan Bersinyal Di Bandung", Tesis, Teknik, Teknik Sipil, ITB, Bandung.

Idris, M. 2007. "Pengembangan Standar Lajur Sepeda Motor Pada Ruas Jalan dan Persimpangan", Puslitbang Jalan dan Jembatan, Departemen Pekerjaan Umum, Bandung.

Idris, M. 2010. "Kriteria Sepeda Motor Untuk Ruas Jalan Arteri Sekunder", Puslitbang Jalan dan Jembatan, Departemen Pekerjaan Umum Bandung.

Nainggolan, Jesicha, dkk. 2018. "Studi Efektivitas Ruang Henti Khusus (RHK) Sepeda Motor Pada Simpang Bersinyal". Jurnal JRSDD, Vol.6, No.3, September 2018, Hal 259-271. Jurusan Teknik Sipil UNILA, Bandar Lampung.

Ratnaningsih, Dwi. 2013. "Analisis Kinerja Simpang Ciliwung Kota Malang". Jurnal PROKONS, Vol.10, No.2, Agustus 2013, Hal 127-131, Jurusan Teknik Sipil POLINEMA, Malang.

Riantara, Youngky, Putra dan Ervina Ahyudanari. 2016. "Simulasi Perencanaan Ruang Henti Khusus Pada Simpang Bersinyal Jalan Dr.Ir.H. Soekarno-Jalan Kertajaya Indah Surabaya Ditinjau Dari Nilai Tundaan", Jurnal Teknik ITS, Vol.5, No.1, 2016, Hal E10-E16, Jurusan Teknik Sipil ITS, Surabaya.

Roesdyningtyas, Ayu, dkk. 2016. "Kajian Rencana Penerapan Ruang Henti Khusus Sepeda Motor Di Persimpangan Bersinyal (Studi Kasus Kota Malang)", Jurnal, Vol.14, No.2, Agustus 2016, Hal 123-129, Jurusan Teknik Sipil UB, Malang. 